\title{
Marine Mammal Behavior: A Review of Conservation Implications
}

\author{
Philippa Brakes * and Sasha R. X. Dall \\ Centre for Ecology and Conservation, Biosciences, College of Life and Environmental Sciences, University of Exeter, \\ Penryn, UK
}

The three orders which comprise the extant marine mammals exhibit a wide range of behaviors, varying social structures, and differences in social information use. Human impacts on marine mammals and their environments are ubiquitous; from chemical and noise pollution, to marine debris, prey depletion, and ocean acidification. As a result, no marine mammal populations remain entirely unaffected by human activities. Conservation may be hindered by an inadequate understanding of the behavioral ecology of some of these species. As a result of social structure, social information use, culture, and even behavioral syndromes, marine mammal social groups, and populations can be behaviorally heterogeneous. As a result responses to conservation initiatives, or exploitation, may be complex to predict. Previous commentators have highlighted the importance of incorporating behavioral data into conservation management and we review these considerations in light of the emerging science in this field for marine

OPEN ACCESS

Edited by:

Mark Peter Simmonds, University of Bristol, UK

Reviewed by:

E. Christien Michael Parsons, George Mason University, USA Andrew Butterworth, University of Bristol, UK

*Correspondence: Philippa Brakes p.brakes@exeter.ac.uk

Specialty section:

This article was submitted to Marine Affairs and Policy, a section of the journal Frontiers in Marine Science

Received: 17 March 2016 Accepted: 19 May 2016 Published: 20 June 2016

Citation: Brakes $P$ and Dall SRX (2016) Marine Mammal Behavior: A Review of Conservation Implications.

Front. Mar. Sci. 3:87. doi: 10.3389/fmars.2016.00087 mammals. Since behavioral canalization may lead to vulnerability, whereas behavioral plasticity may provide opportunity for resilience, we argue that for many of these socially complex, cognitive species understanding their behavioral ecology, capacity for social learning, and individual behavioral variation, may be a central tenant for their successful conservation.

Keywords: marine mammals, sociality, behavior, social learning, culture, individual behavioral variation, personality, conservation

\section{INTRODUCTION}

The extant marine mammals are found in three Orders Cetacea, Sirenia, and Carnivora (including suborder Pinnipedia, Family Mustelidae, and Family Ursidae). These species inhabit a diverse range of habitats from river, brackish, mangrove, and estuarine habitats, to coastal shallows and pelagic seas, with some even foraging at the edge of the abyssal plain. In addition, they have a diverse range of food items, from seagrass or zooplankton, through to fish, penguins, and other marine mammals. As a result of their diverse niches, they exhibit a wide range of behaviors. Some of their behaviors have been studied in detail, whereas others remain more mysterious. For example, the exceptional migration of the baleen whales is well-documented, while details about the more subtle, small-scale behavioral differences between marine mammals social groups is only now starting to emerge.

The importance of incorporating behavioral ecology into conservation efforts has long been argued for terrestrial mammals (Caro and Durant, 1995; Sutherland, 1998; Candolin and Wong, 2012), particularly where manipulations of the wild environment are possible to assist conservation efforts. The challenge that remains is to determine how insights into behavioral ecology can best be used to inform conservation efforts in the more alien marine environment. 
Sociality and social learning are undoubtedly important considerations when conserving marine mammals. In 2010, Whitehead suggested that several factors complicate the conservation of species that learn socially, such as the rapid spread of novel behavior, the evolution of maladaptive behavior, or the inhibition of adaptive behavior (Whitehead, 2010). He argued that such factors have an influence on habitat suitability, responses to anthropogenic change, and even genetic structures. This is reflected in an analysis which revealed that of the toothed whales (Odontoceti), four species showed evidence of decrease in birth rates following exploitation, highlighting the effects beyond the dynamics of individual removals (Wade et al., 2012).

Behavioral variation among populations and individuals also has the potential to influence responses to management efforts and to enhance or hinder conservation. For example, understanding sperm whale (Physeter microcephalus) depredation of sablefish from demersal longlines across the Alaskan fishery has only been possible with emerging knowledge about the scale and spread of this behavior and whether noise from fishing vessels may be providing an acoustic cue for these whales (Thode et al., 2015). While research on killer whale (Orcinus orca) response to an acoustic harassment device, to prevent long-line depredation, indicated habituation to the device (Tixier et al., 2015). However, despite being habituated to the device, exposure to the sound it produces while depredating lines may result in potentially harmful hearing damage (Tixier et al., 2015).

In 1998, Sutherland noted that "The exciting research developments in animal behavior over the last two decades have had a negligible impact on conservation." He then reviewed 20 subjects in which the study of behavioral ecology could make a significant contribution to conservation (Sutherland, 1998). Here, we review this list specifically for marine mammal conservation, in light of the subsequent 18 years of research, and suggest some potential additions to the list.

\section{SMALL POPULATION EXTINCTIONS}

Genetic, ecological, and behavioral factors can all contribute to making small populations particularly vulnerable to extinction. One of the most significant challenges for marine mammal conservation is determining demographically independent conservation units, based on acoustic, taxonomic, genetic, geographic, behavioral, social, or ecological features (Parsons et al., 2015). In highly social species, behavior may play a particularly important role in differentiation between units to conserve and in understanding the mechanisms of population persistence or decline.

Social species may benefit from the presence of conspecifics in a number of ways including predation risk dilution, collective anti-predator vigilance, "selfish herd" effects, predator confusion, cooperative foraging, resource defense, increased availability of suitable mates, allo-parental care, and reduction of inbreeding (Stephens et al., 1999; Krause and Ruxton, 2002). Whilst a handful of marine mammal species are solitary, many are social for at least part of their life cycle and as numbers decrease the ability to raise the alarm, defend against predators, forage, or breed cooperatively also generally declines. The Allee effect (Allee, 1931), which may result in precipitous decline, is defined as a positive relationship between any component of individual fitness and density of conspecifics (Stephens et al., 1999). But it is necessary to differentiate between component Allee effects (at the level of individual fitness) and demographic Allee effects (at the level of mean fitness), which may be important for predicting the persistence of small populations, particularly where a decrease in numbers results in reduced opportunities for cooperation. For example, obligate cooperative breeders rely on a minimum group size to subsist and studies in terrestrial mammals suggest that cooperative breeders (see Section Mating Systems and Inbreeding Depression) may be particularly susceptible to Allee effects. A new conceptual level, the group Allee effect, has been suggested for cooperative breeders (Angulo et al., 2013).

Smaller populations may also place limitations on the ability to find a suitable mate. This may be the result of changes in operational sex ratio as the population declines, which may be related to population density and changes in habitat, but other sexual selection pressures, such as the specifics of mate choice, may also have an influence on population growth rates, making smaller populations more prone to extinction. For example, there is evidence from sperm whaling records that following the reduction in abundance of larger males, that fertility rates were reduced (Clarke et al., 1980; Whitehead et al., 1997). Whether this reduced fertility rate was the result of female mate choice or other selection pressures is unknown.

Nevertheless, it has been suggested that in baleen whales, since male song may influence female mate choice, that preference for local or known dialects could theoretically cause pre-zygotic isolation between species, potentially a precursor to speciation (Beltman et al., 2004; Thornton and Clutton-Brock, 2011). Conversely, it has also been suggested that to avoid inbreeding depression female humpback whales may have a preference for novelty in song, which itself may drive the evolution of the males' song (Parsons et al., 2008).

The matter of how to define a "small population" has conventionally been resolved on genetic or geographic parameters (or both). Nevertheless, from the perspective of determining the influence of behavior for conservation efforts, delimiters based on specific behaviors may also be relevant for predicting population persistence. For example, Southern sea lions (Otaria flavescens), which have declined by over $90 \%$ in the Falkland Islands since the 1930s, exhibit two discrete foraging strategies; inshore and offshore. These strategies appear to be independent of intraspecific competition and are thought to be influenced by foraging site fidelity (Baylis et al., 2015). Using feeding strategies as a boundary between smaller sub-sets of the population may be a vital conservation tool.

In addition, of the three distinct populations of false killer whales (Pseudorca crassiden) recognized around the Hawaiian Islands, a significant difference in fisheries related scarring has been identified between these populations. This suggests that fisheries interactions are occurring at a higher rate in one population, with a bias toward females, suggesting that fisheriesrelated mortality is likely to be disproportionate across these 
distinct populations (Baird et al., 2014). Thus, behavior is relevant for determining "distinct population segments" (DSP) and it has been argued that attempts to limit DSPs to purely "evolutionarily significant units" could compromise management efforts, since the use of demographic and behavioral data would be reduced (Pennock and Dimmick, 1997).

\section{MATING SYSTEMS AND INBREEDING DEPRESSION}

Some marine mammal species, such as sperm whales, killer whales and elephant seals (Mirounga sp.) exhibit dramatic sexual dimorphism, with the males being considerably larger than the females. It has been speculated that species which exhibit communal displays, such as leks may be more prone to small population extinctions (Sutherland, 1998; see Section Small Population Extinctions). Whilst there is only limited data on the mating display of some marine mammals (particularly for those species where mating occurs underwater), sexual dimorphism may provide some clues. In sperm whales it is not known whether copulation is forced by males, chosen by females or determined by other processes (Whitehead, 2003). Nevertheless, there is some evidence that the sexual dimorphism in sperm whales (males being three times the mass of females) tips the balance in favor of "roving" in higher latitudes among the males (up to 27 years), before moving to warmer waters when they begin effective breeding. It has been suggested that the advantages of continuing to feed and grow before seeking out females outweighs the opportunity to breed sooner (Whitehead, 1994), indicating some competitive advantage for larger males. In addition, it has been suggested that difference in feeding ecology between males and females in resident, fish-eating killer whales of the northeastern Pacific Ocean may either be a driver or consequence of sexual dimorphism in this species (Beerman et al., 2016).

Similarly, Northern elephant seals feed separately with males traveling north closer to shore, whereas females migrate west from the coast into the open ocean. Males also forage during benthic dives, whereas female foraging is characterized by pelagic dives interspersed with trips to the sea floor. It has been suggested that this resource portioning is the result of sexual dimorphism, with the females' smaller size necessitating foraging in areas with less predators (Le Boeuf et al., 2000).

Mating behavior clearly has implications for potential inbreeding and conservation. In Antarctic fur seals (Arctocephalus gazella), the territoriality of males and the behavior of females searching for suitable pupping locations are thought to combine to be responsible for the low re-mating frequency (Bonin et al., 2016). Whilst, Wade et al. (2012) noted that in four odontocete species examined there was evidence of a decrease in birth rates following exploitation. Suggested mechanisms include a deficit of adult females, a deficit of adult males, and disruption of mating systems (Wade et al., 2012). In addition, research on California sea lions (Zalophus californianus) suggests that inbreeding may also increase susceptibility to some pathogens (Acevedo-Whitehouse et al., 2003).
It is important to understand the relationship between different breeding systems and inbreeding depression (Sutherland, 1998). Inbreeding depression is the result of non-random mating of close relatives, with a resultant lowering in population fitness. However, the effects of inbreeding are controversial and not always easily predicted (Huisman et al., 2016), as evidenced by the case of the recovering Northern elephant seal (Mirounga angustirostris) population. Despite at one point being reduced to a population of likely $<20$ individuals, this species exhibits significant inbreeding with little genetic diversity and yet the populations do not yet show any obvious signs of inbreeding depression (Weber et al., 2004).

In contrast, the Northern right whale (Eubalaena glacialis) which suffered similar population decimation, failed to make a similar recovery following whaling, with the total minimum population currently estimated at 465 (NOAA, 2015). Research suggests that this population is suffering from reduced fertility, fecundity, and juvenile survivorship. It has been suggested that these factors may be the result of low genetic diversity (in comparison to other right whale populations; Schaeff et al., 1997; Kraus et al., 2001), but that the low genetic variability in this species may be the result of slow but continual erosion of alleles during the last 800 years of the population's decline (Waldick et al., 2002). In addition, there is evidence for post-copulatory gamete selection in right whales, thought to be the result of genetic incompatibility arising from two potential mechanisms: fetal abortion when the offspring are too similar to the mother; or increased fertilization rates and successful pregnancy from genetically dissimilar gametes (Frasier et al., 2013). This may further complicate the influence of mate choice on genetic diversity.

Also in contrast to the Northern elephant seal populations, a small population of Weddell seals at White Island in Antarctica, estimated to be around 80 individuals, is thought to have been founded by only three females and two males. This population exhibits such profound inbreeding that it results in low pup survival (Gelatt et al., 2010).

Nevertheless, along with the Northern elephant seal, Juan Fernandez fur seals (Arctocephalus philippii), is another species that has recovered significantly despite reaching the brink of extinction. Variability in response to inbreeding across marine mammals indicates that some species may be more sensitive to inbreeding depression than others (Hoelzel et al., 2009).

\section{SPECIES ISOLATION}

Behavior, and in particular social learning, may be drivers for speciation (Beltman et al., 2004). But species isolation may cause genetic bottlenecks to develop or create independent evolutionary trajectories. Behavior itself, and particularly social information use, may cause effective population isolation to develop for population segments in sympatry (Riesch et al., 2012).

Extirpation has the potential to remove localized adaptations and potentially eliminate unique evolutionary paths. It has been suggested that for the morphologically and genetically distinct Maritimes walrus (Odobenus sp.) localized extinction 
as a result of hunting, curtailed an evolutionary trajectory that would have enabled this species to evolve along a different path to other north Atlantic walrus (McLeod et al., 2014).

However, hybridization, a spontaneous phenomenon which is suspected in several cetacean (Brown et al., 2014; Hodgins et al., 2014) and pinniped (Lancaster et al., 2010) species also has conservation implications. Depending on the fitness of the hybrids, hybridization may alter gene flow and species boundaries (Lancaster et al., 2010). The effects of hybridization may be difficult to predict in a rapidly changing marine environment (for a review see Schaurich et al., 2012). For sympatric species (living in the same or overlapping habitat), behavioral diversity, such as different habitat use resulting from foraging specializations, may help to reduce encounter rates between species and maintain discrete gene pools (Sobel et al., 2010).

\section{DISPERSAL IN FRAGMENTED POPULATIONS}

The degradation of habitats can lead to the fragmentation of populations and remains an ongoing conservation issue. Key causes of population fragmentation in marine mammals are displacement, through noise, fishing, harassment, or some other environmental stressor, or change in prey abundance or dispersal. Some species may be better equipped to adapt to differing food availability, for example through adapting foraging specializations (Tinker et al., 2008; Ansmann et al., 2012). But other species don't have this flexibility, sirenians are obligate seagrass feeders and thus may disperse into fragmented populations in search of new food patches following extensive damage to seagrass beds (Prins and Gordon, 2014).

Key to predicting how populations may fragment as a result of habitat degradation is an understanding of the range of possible dispersal behaviors. Sutherland (1998) noted a need for a better understanding of how animals search, sample and select new patches (or boarder habitat) and this remains a significant question for marine mammals. This is not only true for resident populations-vs. more transient cohorts-but may also be relevant for understanding changes to migration patterns between critical feeding and breeding habitats. But interpreting responses to disturbance can be complex. Bejder et al. (2006) argue that incorrect application of the term habituation may result from situations where more sensitive individuals have already left a disturbed study area before assessment.

Fragmentation of social groups may be caused by other anthropogenic effects, such as hunting, bycatch, or harassment. Dispersal behavior is also relevant to the rate and extent of the spread of disease. The rate of infection is dependent upon the frequency with which susceptible individuals come into contact with uninfected individuals. For example, elucidation of dispersal and social interactions may be important for predicting transmission of the phocine distemper virus epidemics across harbor seal populations (Phoca vitulina) in north-western Europe (Bodewes et al., 2013).

\section{PREDICTING THE CONSEQUENCES OF ENVIRONMENTAL CHANGE}

Predicting the consequences of environmental change is best understood by looking at the patterns of density dependent processes (Sutherland, 1996) i.e., how vital rates (such as mortality and fertility) are regulated by population density. To understand the role of behavior in some density dependent processes it is necessary to have data on the type of breeding systems, social structure and the transmission of social information within and between populations, as well as an understanding of individual decision making. Such data can be difficult to collect in the marine environment. Nevertheless, some studies provide insights into these processes and may provide opportunities for predicting the consequences of human-induced rapid environmental change (HIREC; Sih et al., 2011) in marine environments.

For example, understanding how population density influences competition (and resource depletion) within feeding habitats may provide some useful insights into the effects of environmental change (Sutherland, 1995). It has also been argued that there are many modulating factors that can influence how wildlife respond to disturbance including; age, anti-predator strategy, habitat type, and even timing of the disturbance. As a result of these many confounding factors, some of which appear to have non-linear and complex effects, the difficulty of finding general patters may be amplified at higher levels of organization toward populations and species (Tablado and Jenni, 2015).

Arguably the most pressing environmental issue of this era, which is increasingly being regarded as the "Anthropocene" (Waters et al., 2016) - because within this epoch human activities are having significant global impact-is the rising atmospheric carbon dioxide and the resultant change in climate. This is producing discernable shifts in marine ecosystems, particularly in relation to temperature, circulation, stratification, oxygen content, and acidification (Doney et al., 2012). From the perspective of marine mammal conservation, it has long been thought that these effects will be most acutely felt in the polar regions, which are particularly vulnerable to sea-ice retreat and which may be the destination of species migrating toward the poles as temperatures rise (Kovacs et al., 2011). Whilst some marine mammals may be able to adapt more readily to rapid change, others may not (Moore and Huntington, 2008). For example, killer whales are now able to access new regions of the Artic as a result of receding sea ice. But as apex predators their presence may have an influence on other marine mammal populations such as beluga (Delphinapterus leucas) and bowhead whales (Balaena mysticetus; Ferguson et al., 2010). It remains unknown whether this expansion of their range is opportunistic, or the result of undocumented environmental pressures.

However, whilst there has been a focus on the effects of climate change on polar and tropical marine ecosystems (such as reef habitat), the effects may be more ubiquitous than first anticipated, with potential range shifts likely to occur across wider latitudes (Lambert et al., 2011). Other species, such as some of the river dolphins and the beaked whales (about which less is known), may 
also face significant challenges as a result of the effects of climate change on their habitat.

Polar bears (Ursus maritimus), have become the flag-ship species for climate change, precisely because they are so vulnerable to changes in sea ice coverage (for a review see Stirling and Derocher, 2012). However, of the 19 subpopulations, there is increasing evidence that response to the loss of sea ice may vary considerably temporally and geographically and may be related to density-dependent effects (Rode et al., 2014). This variability among sub-populations highlights the difficulty of providing accurate general population projections, where perhaps subpopulation projections would be more helpful, especially in light of the rate of change within the summer and winter sea-ice coverage.

\section{REDUCING PREDATION}

Whilst introducing predators is not common practice in the marine environment, reduced predation from marine mammals can be a goal for some fisheries. One solution is the culling of predators, which has ethical and welfare considerations and its efficacy is controversial (Yodzis, 2001). Invariably, it is more appropriate to deploy non-lethal methods to manipulate predator behavior, such as seal scarers, an acoustic repellent system (for examples see: Schakner and Blumstein, 2013). Successful outcomes are dependent on an accurate assessment of the interaction between predator and fishery (which can be elusive; Morissette et al., 2012) and the deployment of such a device may also cause disturbance, or displacement, for other marine mammals besides the target species. In such cases, maintaining fish stocks for exploitation is, strictly speaking, not a conservation goal but rather an industry goal, which often neglects the importance of diversity within food webs and ecosystems, or the implications of the impact of commercial fisheries on marine mammal populations (DeMaster et al., 2001).

Sutherland (1998) argues that research on individual or social learning can have an important role in tackling conservation issues associated with predation (Sutherland, 1998). Research on dugong avoidance of sharks showed, unsurprisingly, that in relatively dangerous shallow habitat, dugongs avoided continuous series of resting bouts in the presence of these predators. Whereas, in deeper water habitats their response to the presence of sharks were more modest (Wirsing and Heithaus, 2012). Data on the range of natural responses to predators may be particularly useful for addressing conservation issues associated with excessive predation of endangered species.

Population size may also be an important factor in relation to predicting the consequences of predation. For example, when Steller sea lions (Eumetopias jubatus) were less abundant in the Aleutian Islands (1990s) and in Southeast Alaska (1960s) predation by killer whales was thought to influence population projections. However, predation by killer whales seemed to have little effect when the populations became more abundant (Guénette et al., 2006).

\section{RETAINING CULTURAL SKILLS}

Research on non-human culture has progressed a pace, particularly in cetaceans since Sutherland (1998) identified these original 20 areas of interest (see for example Rendell and Whitehead, 2001; Whitehead and Rendell, 2015). Social learning is a prerequisite for culture, which can be defined as: "information or behavior-shared within a community-which is acquired from conspecifics through some form of social learning" (Whitehead and Rendell, 2015, p. 12). Social learning and culture are not only relevant to terrestrial conservation in terms of ensuring that captive-bred or translocated animals have the rights skills to survive in the wild (as Sutherland (1998) suggests), but culture is also now recognized as having important implications for the conservation of wild populations (Whitehead, 2010; CMS, 2014).

Whilst there are many types of learning, social learning is arguably the most relevant to the consideration of the conservation of marine mammals. Social learning can entail fewer costs to the individual than individual learning and enables novel behavior to spread rapidly, so adaptation can occur faster than through genetic change alone (Boyd and Richerson, 1985). HIREC may provide a number of novel cues and opportunities for social learning for marine mammals, generating unique selection pressures. It has been argued that " $\mathrm{a}$ cognitive mechanism that causes avoidance of novel food is as encumbering as a specialized feeding apparatus that prevents an animal from eating that food" (Greggor et al., 2014, p. 490). It can similarly be argued that the learning of a social norm and the drive to conform may likewise inhibit the spread of adaptive behavior, in a similar manner to neophobia (fear or dislike of anything new or unfamiliar).

But the occurrence and consequences of innovations can be difficult to predict. Malthus (1798) famously predicted that the projected increase in human populations would lead to "vice and misery," but failed to account for the fact that humans had the capacity to innovate and socially transmit methods for increasing their own food supply (Davies et al., 2012). Nevertheless, caution should be applied when predicting how social learning may assist or hinder wildlife adaptation to change as there may be anthropogenic (Donaldson et al., 2012), ecological, cognitive (Greggor et al., 2014), or cultural (Whitehead, 2010) interactions and constraints in play. There is also evidence for individual variation in social learning within species and a continuum of phenotypic plasticity (i.e., a range of ways in which the genes can manifest in different environments) has been suggested (Mesoudi et al., 2016).

Social learning in marine mammals is most famously evidenced in the transmission of humpback whale song (Megaptera novaeangliae; Noad et al., 2000; Garland et al., 2011) and more recently through the spread of a novel feeding method, known as "lobtail feeding" (Allen et al., 2013). The occurrence of these two apparently independent elements of social learning suggest that this species can maintain more than one independently evolving culture (Allen et al., 2013).

Social transmission and cultural constraints may influence conservation outcomes. North Atlantic right whales (E. glacialis) have shown a very poor recovery following intensive whaling 
during the sixteenth and seventeenth centuries. Right whales are now almost entirely absent in the waters of Labrador (Katona and Kraus, 1999). It is thought that whilst oceanic climate change may play a role in this lack of recovery, perhaps the removal of such a significant proportion of the population through whaling destroyed cultural knowledge about critical habitat, or other significant cultural knowledge that may be inhibiting recovery (Whitehead et al., 2004).

Also, since baleen whale calves are thought to learn migratory routes and likely other habitat knowledge from their mothers, such as the location of critical feeding or breeding habitat, or areas of high predator density, some may be more reluctant to explore new areas, culminating in slower range recovery following extirpation (Clapham et al., 2008; Carroll et al., 2011, 2014; Baker et al., 2013). It has been suggested that loss of cultural knowledge and resultant limited range recovery may be one factor inhibiting a recovery of the North Atlantic right whale population (Mate et al., 1997). This has been demonstrated for southern right whales (Eubalaena australis) where, following extensive whaling, the remaining populations are now limited to two distinct feeding areas as a result of maternally directed site fidelity, despite the availability of other suitable feeding habitat (Carroll et al., 2014, 2016).

Research on the social structure of migrating beluga whales (D. leucas), an odontocete species, also suggests that cultural conservatism enables social groups to learn migratory routes. However, a potential cost may be that this conservatism could impede the re-colonization of extirpated areas (Colbeck et al., 2013).

As well as ecological cultural knowledge, conservative cultures, in which individuals must conform in order to "fit in," may lead to the suppression of novel behaviors. Conformist cultures may inhibit adaptive learning, with preference for cultural norms potentially suppressing ecologically useful behavioral adaptations, or leading to valuable habitats being overlooked (Whitehead, 2010). A striking example of this is provided by the southern resident population of killer whales which feed preferentially on chinook salmon (Oncorhynchus tshawytscha; Ford and Ellis, 2006). It is argued that since these killer whales seem very reluctant to use a variety of other prey-items available to them, this conformist prey specialization may be a constraint on the population's resilience, since it is contingent on the availability of the salmon (Ford et al., 2010; Whitehead, 2010). In addition to prey preferences, cultural conformism may also inhibit an individual's adaptive use of space, through dispersal or migration. For example, it has been suggested that killer whales may continue to use traditional areas despite increases in chemical and noise pollution (Osborne, 1999).

Whitehead suggest that in some instances cultural behavior may be maladaptive (Whitehead, 2010) and that mass stranding of species such as the highly social pilot whales may be at least partly be associated with conformist cultures (Rendell and Whitehead, 2001). Nevertheless, there are many other possible causes of mass stranding and the difficulty in such instances is to separate out anthropogenic, cultural and other natural causes.
Sutherland (1998, p. 804) noted: "A better understanding of cultural evolution would have considerable consequences for conservation." Although, social learning has been identified in many terrestrial mammals (Thornton and Clutton-Brock, 2011), research on social learning and investigation into potential unique cultures in other marine mammals species besides cetaceans is limited. This is an area where directed examination of social transmission across all marine mammal species would likely benefit conservation efforts in the future.

\section{BEHAVIORAL MANIPULATIONS}

Many terrestrial conservation projects involve manipulating behavior (Sutherland, 1998). This is rarer in the marine environment, where such manipulations can be more challenging. As far as the authors are aware, there are no conservation schemes to alter the migration routes of marine mammals, or reserves set up with the sole intention of attracting marine mammals to a formerly uninhabited area. Instead there is emphasis on reducing environmental threats and identifying critical habitat (particularly breeding or feeding habitat) for protection (Hoyt, 2011).

Nevertheless, non-lethal deterrents are used to manipulate marine mammal behavior, with efforts focused on reducing bycatch and depredation from fisheries. Such deterrents act by creating the sense of a perceived risk associated with utilizing the resource, often with the use of sound (Schakner and Blumstein, 2013). But such manipulations could be improved with insights from comparative cognition (Greggor et al., 2014).

Successful mitigation of environmental threats and identification of critical habitat requires a good understanding of the behavioral ecology of the species and population specific behavior. Some instances of behavioral manipulation in marine mammals arise as the result of opportunistic interaction with humans, although these may not necessarily be directly associated with conservation efforts, they may have conservation implications.

Interactions with human activities, such as co-operative fishing (Daura-Jorge et al., 2012), trawling (Chilvers et al., 2001; Pace et al., 2011; Ansmann et al., 2012), depredation (i.e., taking fish from fishing gear; Esteban et al., 2016b), provisioning, or begging (Mann and Kemps, 2003; Donaldson et al., 2012), can provide a novel foraging niche, which marine mammals can learn to utilize through social transmission. As a result there is a risk of social groups becoming dependent on these human activities, in what has been termed "anthropo-dependence" (CMS, 2014).

\section{RELEASE SCHEMES}

Release of marine mammals into the wild is relatively rare (in comparison with terrestrial mammal breeding and release schemes), but sea otter recovery from near extinction in the 1700 s and 1800s has been facilitated by conservation release schemes. Nevertheless, recovery to the full extent of their former range has been sporadic, possibly as a result of problems with habitat quality and research on the influence of age, sex, or social 
structure on dispersal into new habitat may enable predictions of future distribution (Lafferty and Tinker, 2014).

For other marine mammals species release is more common in relation to rescue and rehabilitation. Whilst there are strong welfare motivations for rescue and release-and rescue and release can be successful (Sharp et al., 2016) - a number of significant issues associated with the release of marine mammals have been identified. These include: potential conflict with fisheries, ignorance of recipient population ecology, genetic disparity, and the potential for the spread of novel or anti-biotic resistant pathogens (Moore et al., 2007). In addition, depending on the circumstances and longevity of the rehabilitation period, there are potential issues associated with finding suitable social units with corresponding culture or social knowledge for a release candidate. Also, for young rescued and rehabilitated mammals, such as harbor seal (P. vitulina richardii) pups, there is evidence that a developmental window associated with learning specific behaviors from their mothers may be missed if rehabilitation occurs during the nursing period (Gaydos et al., 2013). This highlights the need to integrate a species behavioral ecology into decision making about rescue and release schemes for marine mammals.

\section{HABITAT REQUIREMENTS OF SPECIES OF CONSERVATION CONCERN}

In order to determine habitat requirements for any marine mammal of conservation concern, it is essential to have information on the diversity of prey, home range, sensitivities to specific anthropogenic threats (such as noise from vessel traffic, entanglement etc.) and knowledge about breeding behavior. Understanding social structure and dispersal behavior are also likely to be important. But for some marine mammal species (particularly those that exhibit some degree of foraging plasticity), it is important to ensure that protected habitats are sufficiently diverse (for example by including steep sloping habitat) that they offer opportunities for new foraging strategies or prey items, to provide resources for resilience to HIREC through innovation and social learning.

Under the United States Endangered Species Act of 1973 (ESA; 16 U.S.C. $\$ 1531$ et seq.), critical habitat should provide the physical and biological features essential to the conservation of endangered or threatened species. For marine mammals these features include: space for individual and population growth and normal behavior; shelter; food, water, air; and sites for breeding and rearing offspring. In addition, critical habitat may also include areas beyond the species range at the time of listing, but which are considered essential to their conservation.

Killer whales have been shown to be more vulnerable to disturbance from vessels when they are feeding, rather than when resting, traveling, or socializing, leading to the recommendation that protected area management strategies should target feeding "hotspots," thus prioritizing the protection of habitat used for the behavior in which a species is most vulnerable to anthropogenic disturbance (Ashe et al., 2010).
Defining critical habitat for migratory species can be particularly challenging. Different types of habitat may have several functions for some migratory species. For example, in humpback whales it has been suggested that subarctic feeding grounds provide not only an opportunity for foraging but also for song progression and exchange and may act as opportunistic mating grounds for migrating or overwintering whales (Magnúsdóttir et al., 2015).

\section{MINIMUM AREA NECESSARY FOR RESERVES}

There are many challenges associated with determining the size and composition of marine protected areas or reserves for highly social marine mammal species. Among the various threats to marine mammals which reserves can help to mitigate are fisheries entanglement, bycatch, prey depletion, and ship strikes. Protecting cetacean habitat from anthropogenic noise may be a particularly salient consideration in relation to behavioral ecology (see Section Noise and Behavior), particularly where noise overlaps with communication or echolocation (Melcón et al., 2012; Veirs et al., 2015).

Sound can travel much greater distances in water than in air and the range over which some of the larger marine mammals may be in social contact with each other may even extend to the level of ocean basins (Whitehead and Rendell, 2015). As a result marine protected area networks and zoning are an essential tool for ensuring the integrity of marine mammal populations (Hoyt, 2011). Protecting "opportunity sites" has also been suggested to capitalize on protecting important wildlife habitat that already has low anthropogenic noise (Williams et al., 2015).

Behavior is clearly relevant in relation to delineation of marine protected areas. The challenge is determining which behavior is either the best indicator, or the most vulnerable to anthropogenic threats (see Section Habitat Requirements of Species of Conservation Concern). For example, Bryde's whales (Balaenoptera edeni) around the coast of Brazil may use coastal areas for feeding and migrate to deeper oceanic habitat for breeding (Gonçalves et al., 2015), highlighting the need for protected areas to encompass the range of lifecycle events associated with vital rates, with connectivity between critical habitat.

Since culture can evolve faster than genetic lineages, marine mammals that exhibit social learning and the transmission of culture may also require more regular review of marine protected areas and their efficacy: as behaviors change and culture evolves, habitat requirements may change. Whilst some cultures may be very stable and may last many generations, some cultures may evolve more rapidly in response to changes in the environment. Where possible, this should be accounted for at the outset, by ensuring that protected areas are large enough to accommodate such shifts and by ensuring management plans include areas with flexible high protection zones (Hoyt, 2009, 2011). This type of adaptive and dynamic management (Bengtsson et al., 2003; Game et al., 2009) is important for resilience. For example, if dramatic 
shifts in behavior as a result of rapid social learning occur that have implications for conservation, plans can be adapted.

In addition, it has been argued that during designation of marine protected areas, attention should be paid to the wider ecosystem and how this supports specific habitat and behaviors. For example, for killer whale populations that feed on salmon, consideration should not only be given to the habitat in which these whales are feeding, but also to the river systems which support their prey (Hoyt, 2009, 2011; Ashe et al., 2010).

\section{CAPTIVE BREEDING}

Captive breeding for marine mammals is fraught with difficulty, largely as a result of the challenges associated with successfully reproducing the unique physical and social environment required for these species, particularly those with extensive home ranges. For example, researchers recorded a killer whale traveling from the Antarctic Peninsula to Brazil and back again over the course of just 42 days, a journey of some $9400 \mathrm{~km}$ (Durban and Pitman, 2012).

But the physical limitations of the captive environment are only part of the picture. Providing the right social environment for mating and successful rearing of offspring of highly socially marine mammals may be particularly challenging. For example, in the wild, killer whales live in multi-generational societies, with distinct ecotypes differing in morphology, communication, prey, and foraging strategies (Pitman et al., 2010; Riesch et al., 2012). These complex societies cannot be replicated in the captive environment and although killer whales of different ecotypes may produce viable offspring in captivity, these hybrids are unlikely to be suitable for release. It is argued that the failure to successfully reintroduce the captive killer whale know as Keiko back into the wild, who more readily associated with dolphins than killer whales from his own pod, suggests that correctly assimilating cultural traditions could be age specific (Simon et al., 2009; Riesch et al., 2012).

As a result, compared with fertility rates in the wild, captive breeding rates and survival to age milestones for some species, such as killer whales, are poor (Small and Demaster, 1995; Jett and Ventre, 2015). The emerging knowledge on the behavioral ecology of many of the larger marine mammals is unlikely to ameliorate this problem, but instead serve to demonstrate lack of suitability for successful captive breeding and re-introduction (see also Section Release Schemes).

\section{REPRODUCTIVE BEHAVIOR AND REPRODUCTIVE PHYSIOLOGY}

Sutherland (1998) posits that opportunities for manipulating reproductive behavior and physiology in wild populations are underexplored. Whilst this remains true for many marine mammal species, this approach has many practical difficulties, particularly for those marine mammals that live their entire lifecycle in the water. But even for those species that spend some time on land, from the perspective of practicality and economics, there is likely more merit is exploring the conditions, both social and environmental, required for optimal breeding in the wild.
Reproductive behavior in marine mammals includes polygyny and promiscuity and pinnipeds species that breed on land compete for reproductively active females by defending breeding territories. Notably, those pinnipeds that breed in the water or on ice (walrus and ice seals), which may have more difficulty defending an unstable environment, tend to be less polygynous. Cetaceans exhibit a range of mating strategies. Toothed cetaceans tend to exist in social groups, which may indicate an important role for others in the rearing of offspring (allo-parental care). Whereas, the basic social unit in baleen whales is considered to be the cow-calf pair, with shorter periods of maternal care than in the toothed cetaceans (for a full dicussion of marine mammal mating systems see: Berta et al., 2015). Nevertheless, the role of a male or female "escort" to a humpback whale cow-calf pair remains under debate and highlights the need for further research on some aspects of marine mammal mating systems in order that conservation efforts can target optimal conditions for breeding.

\section{CENSUS TECHNIQUES}

For marine mammals that spend most or all of their life cycle in the water, census techniques have to make assumptions about the likelihood of being "caught" (for example during mark recapture techniques). Better understanding of surfacing behavior, or regularity and range of vocalizations, as well as knowledge of dispersal across patchy habitat, may enhance the resolution of some census techniques, particularly for more cryptic species, such as the beaked whales (Yack et al., 2013). One technique in particular, which aims to quantify song dynamics and identify individual humpback whales by their distinct vocalizations, holds promise as a population identifier for monitoring trends across vast habitat (Garland et al., 2013) and the use of environmental DNA (eDNA) in marine habitats may also assist in understanding dispersal, by detecting the presence or absence of some species (Foote et al., 2012). In addition, molecular census techniques used to elucidate dispersal patterns and fragmentation in cryptic terrestrial mammals, such as the giant panda (Ailuropoda melanoleuca; Zhan et al., 2006) may have application for marine mammals, where adequate fecal sampling is practical.

\section{EXPLOITATION}

Patterns of exploitation are influenced by the behavior of both hunters and their prey (Sutherland, 1998). Similarly, the distribution of whaling vessels has been compared with the ecological theory of ideal free distribution, in which the number of individuals that will aggregate in various patches of resource is proportional to the amount of resource available in each patch. However, records of sperm whaling in the Galapagos Islands in the 1800s, suggest a violation of the ideal free distribution. It is speculated that this may be a result of inaccuracies in the information available to these early whalers (Whitehead and Hope, 1991).

For many marine mammals the history of hunting is well-chronicled, but the numbers taken is often less welldocumented (Ivashchenko et al., 2011; Ivashchenko and 
Clapham, 2015). As a result determining pre-exploitation abundance can be challenging and controversial. For example, models for mDNA sequence variation provide estimates for North Atlantic fin (Balaenoptera physalus physalus) and humpback ( $M$. novaeangliae) whale populations 6 to 20 times higher than present day populations (Roman and Palumbi, 2003).

One important potential behavioral issue of concern for exploited marine mammals is the buffer effect, where at low densities individuals concentrate in the best habitat, but at higher densities are more dispersed over a wider area (Brown, 1969). This can give a false indication of abundance to hunting communities searching in localized areas of high density, whilst the overall population may be in decline. This may be an important consideration in the geo-political wrangling between whalers, scientists, and governments, and in decision making on protection of polar bear habitat (Rode et al., 2014). Sutherland (1998) contends that it is precisely this effect that led to the confidence of the fishing community which brought about the collapse of the Atlantic cod (Gadus morhua) fishery off the eastern-coast of Canada. Marine mammal conservation efforts will doubtless benefit from improved knowledge of dispersal trends, particularly in relation to changing environments and patchy distribution of resources.

\section{INCREASE IN HUMAN POPULATION}

Sutherland (1998) notes: "the overwhelmingly important problem to humanity and biodiversity is the increase in human population." Since the paper's publication in 1998 there are around 1.4 billion additional humans on the planet and although the growth rate has dropped a little, the total human population is likely to rise to around 9.6 billion by 2050 (UNFPA, 2011). While reproductive decision making is a behavioral ecology issue, even within our own species (Sutherland, 1998), there are also many socio-economic issues related to the decision processes and this topic remains both largely taboo (a cultural issue) and the single biggest threat to conservation efforts.

The human population explosion, combined with the procurement and use of fossil fuels-in particular the ubiquitous use of plastics, which accumulate in the marine environmentremains one of the largest threats to marine mammal populations (Simmonds, 2012). This is particularly true for species inhabiting coastal areas where the impacts are often more concentrated (Brakes and Simmonds, 2011). But solutions to problems such as marine debris are not always straight forward. It was hoped that the introduction of biodegradable plastics would go some way toward curbing the marine plastics issue. However, it is now thought that the biodegradation of plastics occurs in conditions rarely met in the ocean environment (Kershaw, 2015) and that other solutions must be sought.

\section{DISCOUNTING}

It has been asserted that discounting by human decision-makers favors the over-exploitation of long-lived species as the long-term benefits of sustainable yield once discounted, may be less than the short-term benefit of overexploiting (Clark, 1990; Henderson and Sutherland, 1996). Discounting is potentially a problem for some marine mammal species, which are often long-lived and lowly fecund. Whilst sustainability of resource use into the future may in some cases temper over-exploitation, the basic discounting principle that the opportunity to utilize a resource now, combined with the risk that these resources may not be available in the future, can drive over-exploitation of marine mammals populations (Ivashchenko et al., 2011; Ivashchenko and Clapham, 2015) and may be a motivation for under reporting. Whilst there are some legal and practical conservation measures designed to prevent over exploitation, the uncertainty associated with the potential effects of climate change and other threats to marine mammal populations could potentially lead hunters to favor higher discount rates, particularly if the likelihood of population persistence into the future is uncertain.

\section{INCREASE IN CONSERVATION CONCERN}

Sutherland (1998) predicted that public and media interest in behavioral ecology has a considerable role in encouraging interest in conservation and shaping the views of the next generation of biologists. Indeed, public interest in animal behavior in wild populations has only increased in the last 15 years with improvements in technology and a proliferation of media outlets for wildlife documentaries and news. Insight into the lives of marine megafauna has benefitted from this revolution as the deployment of affordable remote monitoring technology continues to burgeon. This is leading to a golden age of discovery of the lives and habits of many marine mammals species.

Research comparing public attitudes toward wildlife between the United States, Japan and Germany highlighted that differing attitudes are the result of biogeographical and cultural difference between countries (Kellert, 1993). Later research on public attitudes toward dolphins suggested that these species remain poorly understood by the wider public with potentially harmful behaviors toward wild dolphins being widespread (Barney et al., 2005). More recent research in the Caribbean island of Aruba, where there is not yet a whale watching industry, indicates that support for marine mammal conservation among residents is high, whilst knowledge about species richness and identity is low, suggesting that detailed knowledge is not necessarily a prerequisite for positive public attitudes toward conservation (Luksenburg and Parsons, 2014).

\section{CONSERVING BEHAVIOR}

It has been argued that specific behavior, such as wildebeest (Connochaetes sp.) migrations or bathing in hot springs by Japanese Macaques (Macaca fuscata) may be of sufficient interest to warrant conservation in itself (Sutherland, 1998). Whilst the emphasis of conservation bodies such as the IUCN is on maintaining genetic diversity, there is a strong argument that maintaining behavioral diversity may also play a central role in ensuring sufficient variety for resilience to environmental change. 
It can perhaps further be argued that some non-human cultures, such as some of those exhibited by whales and dolphins, may be worthy of preservation for their own intrinsic value, irrespective of their potential facility to species conservation. UNESCO (the United Nations Education, Scientific and Cultural Organization) argues that cultural heritage extends not only to objects and monuments, but also encompasses behaviors inherited from our ancestors including "oral traditions, performing arts, social practices, rituals, festive events, knowledge, and practices concerning nature and the universe or the knowledge and skills to produce traditional crafts" (UNESCO, 2016). Whilst many of these remain uniquely human cultures, there is strong evidence among whales and dolphins for culture including, vocal dialects, the transmission of migratory routes, and knowledge about tool use (Whitehead and Rendell, 2015; see Section Retaining Cultural Skills). If we consider that knowledge may be as vital a currency as genes for some social species, maintaining the diversity of non-human intangible cultural heritage may be as important for some marine mammals as it is for humans.

\section{CONSEQUENCES OF ENVIRONMENTAL CHANGES ON BEHAVIOR}

The implications of behavior for conservation of marine mammals have been reviewed here extensively. But Sutherland (1998) also argued that it is important to consider the implications of environmental change on behavior itself. Specifically it is important to consider how environmental change, including exploitation, may create selection pressures that may influence marine mammal behavior.

Acknowledging the limitations of the data reviewed, Wade et al. (2012) argue that odontocetes (toothed cetaceans) may be less resilient than mysticetes (baleen whales) to overexploitation. In contrast, research on the restructuring of a dolphin population following a change in human use of the environment from trawling to post-trawling periods within Moreton Bay, Australia, showed that since the reduction in trawling the social networks of the two social groups had become less differentiated and that previous partitioning into two communities disappeared (Ansmann et al., 2012). These contrasting findings highlight the complexity with which social dynamics may be influenced by differing anthropogenic environmental change and how some species and populations may demonstrate adaptability and be more robust to change, whereas others may be less resilient. This complexity may be further compounded by the synergistic manner in which some anthropogenic threats may operate, making forecasting the consequences for behavior a greater challenge.

Marine mammals inhabit a vast array of habitats and as a result threats from HIREC are myriad. It is also important to consider the spatio-temporal scale of the species in question when assessing changes in behavior as a result of environmental factors (Lomac-Macnair and Smultea, 2016).

\section{NOISE AND BEHAVIOR}

One anthropogenic threat, not singled out by Sutherland (1998) but of specific relevance to marine mammal behavior, is noise. Sound travels more than four times faster in water than in air and noise, whether natural or anthropogenic, can interfere with marine mammal communication, sociality, navigation, and foraging (particularly for those species that echolocate). Nevertheless, whilst noise is a natural phenomenon in the oceans, there is evidence that humpback whales may not be able to cope with an increase in anthropogenic noise in the same way that they offset fluctuations in natural noise (Dunlop, 2016).

As anthropogenic ocean noise increases there is concern that the effects of auditory masking may be having far reaching effects for some marine mammals populations (Erbe et al., 2015). The effects of noise may not be limited just to the receiver. The Lombard (1911) effect predicts that noise may elicit antimasking behavior in the sender, for example changing call rate or frequency. For example, research on fin whale (B. physalus) 20$\mathrm{Hz}$ song showed that male fin whales modify song characteristics under increased background noise resulting from shipping and seismic air guns (Castellote et al., 2012).

Several theories have been posited as to the cause of the decline in tonal frequencies of blue whale song, such as increasing ocean noise, sexual selection, increasing population recovering following exploitation, competition with other species, such as fin whales and even ocean acidification (McDonald et al., 2009). However, it has also been suggested that social learning may have played a role in this now worldwide phenomenon (Whitehead and Rendell, 2015), which may be the result of anti-masking behavior.

Potential effects of noise on the lower frequency communication of the baleen whales has been under discussion for some time, but there is now evidence that the range of frequencies emitted by various types of shipping traffic within coastal areas include higher frequency noise within the range used by killer whales for both communication and echolocation (Veirs et al., 2015).

\section{FURTHER CONSIDERATIONS}

Whilst the synergies between behavioral ecology and conservation science have blossomed in the years since Sutherland (1998) raised the issue of disconnect between these two fields, the examination of his 20 key areas of interest shows that there is still a considerable way to go for behavioral ecology to be fully incorporated into conservation science and policy making for marine mammals.

In addition to the 20 key areas raised by Sutherland, there are arguably a number of other emerging issues in behavioral ecology that also warrant consideration for marine mammals, including different social learning mechanisms, social structure, social role, and personality.

Social information and fine scale social structure (Williams and Lusseau, 2006; Kurvers et al., 2014; Esteban et al., 2016a) may strongly influence social dynamics and potentially vital rates. These influences may be synergistic or opposing and 
warrant a more sophisticated approach toward managing social species, particularly those which exhibit social transmission.

How social segments within marine mammal populations are connected and how information flows between them also requires further elucidation (for example see: Rendell et al., 2012; Filatova et al., 2013), particularly since multi-level societies may have differing behavioral responses to anthropogenic change (Whitehead et al., 2012; Cantor et al., 2015). The roles of individuals within their social groups and even the ontogeny of senescence may have important implications for survivorship and conservation (Brent et al., 2015).

Since maintaining behavioral diversity is important for adaptation to novel environments, one of the principle goals of conservation, beyond conserving genetic biodiversity, should also be to conserve a wide range of behaviors and in some populations this may also include protecting discrete cultural units.

Understanding behavioral plasticity is also undoubtedly an important consideration for predicting how a species may respond to changes in their environment. The degree of plasticity within behavioral repertoires may provide important opportunities for adaptation (Ansmann et al., 2012; Mann et al., 2012). Although resilience as a result of behavioral plasticity may act as a buffer to ecological change, there is also concern that behavioral adaptation could mask emerging ecological issues. For example, whilst a species may switch prey in the face of ecological pressures, if such buffers then become exhausted the consequences of change could be more rapid (CMS, 2014). This highlights the need to monitor changes in prey choice for endangered species that exhibit a high degree of behavioral plasticity.

In addition to the more general characterization of a species overall behavioral plasticity, behavioral syndromes, consistent individual differences in behavior (CIDs or personality variation) may influence individuals' ability to cope with novel conditions (Sih et al., 2004). For example, individuals with flexible, exploratory, bold, or aggressive behavioral tendencies may be able to cope better with HIREC (Sih et al., 2011). However, in captivity there are concerns that reduced behavioral diversity and selection for personality traits that better suit the captive environment may lead to propagation of personality types and behavior that is illsuited for the wild, potentially reducing viability for successful release (Carere and Maestripieri, 2013).

For a discussion on the consequences of animal personality for population persistence and social dynamics see Wolf and Weissing (2012). However, empirical studies into personality variation in wild marine mammals are rare (see for example:

\section{REFERENCES}

Acevedo-Whitehouse, K., Gulland, F., Greig, D., and Amos, W. (2003). Inbreeding: disease susceptibility in California sea lions. Nature 422, 35. doi: $10.1038 / 422035 \mathrm{a}$

Allee, W. C. (1931). Animal Aggregations. A study in General Sociology. Chicago, IL: University of Chicago Press.
Estes et al., 2003; Twiss et al., 2012) and are likely to remain so for some of the more enigmatic species, such as the beaked whales. But even for those more accessible marine mammals whose behavioral repertoires and ecology are well-researched it is important not to conflate behavioral polymorphism with personality variation. An empirical framework for evaluating personality variation has been suggested to avoid such pitfalls (Dall and Griffith, 2014).

\section{CONCLUSION}

There is no doubt that a better understanding of the behavioral ecology of many marine mammals is important for their conservation. It is difficult to envision any approach toward conserving a population of modern humans, which merely preserved their genetic integrity and did not also consider their behavior. We have some understanding and experience of the complexity of human decision making: amid our different cultures, environments, and circumstances we make choices about what to eat, who to socialize with, where to live, how many offspring to have etc. All of which can influence our fertility rates and survival.

Similarly, while efforts to conserve marine mammal biodiversity focus strongly on maintaining genetic integrity and diversity, the emerging evidence indicates that sociality and behavioral diversity may also be central to individual, social group, and population viability. The challenge ahead is teasing out the most relevant factors and understanding how to incorporate this new knowledge into management models and conservation efforts for marine mammals.

\section{AUTHOR CONTRIBUTIONS}

PB initiated the review and with assistance and comments from SD developed the revised manuscript.

\section{FUNDING}

Lead author's research is funded by WDC (Whale and Dolphin Conservation). Article submission has been funded by the Humane Society International (HSI) as part of their funding for this special edition.

\section{ACKNOWLEDGMENTS}

The authors would like to thank Erich Hoyt, Regina AsmutisSilvia, and Mark Simmonds for helpful comments and conversations during the development of this manuscript. 31976

Angulo, E., Rasmussen, G. S., Macdonald, D. W., and Courchamp, F. (2013). Do social groups prevent allee effect related extinctions?: the case of wild dogs. Front. Zool. 10:11. doi: 10.1186/1742-9994-10-11 
Ansmann, I. C., Parra, G. J., Chilvers, B. L., and Lanyon, J. M. (2012). Dolphins restructure social system after reduction of commercial fisheries. Anim. Behav. 84, 575-581. doi: 10.1016/j.anbehav.2012.06.009

Ashe, E., Noren, D. P., and Williams, R. (2010). Animal behaviour and marine protected areas: incorporating behavioural data into the selection of marine protected areas for an endangered killer whale population. Anim. Conserv. 13, 196-203. doi: 10.1111/j.1469-1795.2009.00321.x

Baird, R. W., Mahaffy, S. D., Gorgone, A. M., Cullins, T., McSweeney, D. J., Oleson, E. M., et al. (2014). False killer whales and fisheries interactions in Hawaiian waters: evidence for sex bias and variation among populations and social groups. Mar. Mammal Sci. 31, 579-590. doi: 10.1111/mms.12177

Baker, C., Steel, D., Calambokidis, J., Falcone, E., González-Peral, U., Barlow, J., et al. (2013). Strong maternal fidelity and natal philopatry shape genetic structure in North Pacific humpback whales. Mar. Ecol. Prog. Ser. 494, 291-306. doi: 10.3354/meps 10508

Barney, E. C., Mintzes, J. J., and Yen, C.-F. (2005). Assessing knowledge, attitudes, and behavior toward charismatic megafauna: the case of dolphins. J. Environ. Educ. 36, 41-55. doi: 10.3200/JOEE.36.2.41-55

Baylis, A. M. M., Orben, R. A., Arnould, J. P. Y., Peters, K., Knox, T., Costa, D. P., et al. (2015). Diving deeper into individual foraging specializations of a large marine predator, the southern sea lion. Oecologia 179, 1053-1065. doi: 10.1007/s00442-015-3421-4

Beerman, A., Ashe, E., Preedy, K., and Williams, R. (2016). Sexual segregation when foraging in an extremely social killer whale population. Behav. Ecol. Sociobiol. 70, 189-198. doi: 10.1007/s00265-015-2038-2

Bejder, L., Samuels, A., Whitehead, H., and Gales, N. (2006). Interpreting shortterm behavioural responses to disturbance within a longitudinal perspective. Anim. Behav. 72, 1149-1158. doi: 10.1016/j.anbehav.2006.04.003

Beltman, J. B., Haccou, P., and Ten Cate, C. (2004). Learning and colonization of new niches: a first step toward speciation. Evolution 58, 35-46. doi: 10.1111/j.0014-3820.2004.tb01571.x

Bengtsson, J., Angelstam, P., Elmqvist, T., Emanuelsson, U., Folke, C., Ihse, M., et al. (2003). Reserves, resilience and dynamic landscapes. Ambio 32, 389-396. doi: 10.1579/0044-7447-32.6.389

Berta, A., Sumich, J. L., and Kovacs, K. M. (2015). Marine Mammals: Evolutionary Biology. Amsterdam: Elsevier Science.

Bodewes, R., Morick, D., van de Bildt, M. W., Osinga, N., Rubio García, A., Sánchez Contreras, G. J., et al. (2013). Prevalence of phocine distemper virus specific antibodies: bracing for the next seal epizootic in north-western Europe. Emerg. Microbes Infect. 2:e3. doi: 10.1038/emi.2013.2

Bonin, C. A., Goebel, M. E., O'Corry-Crowe, G. M., and Burton, R. S. (2016). Impacts of ecology and behavior on Antarctic fur seal remating and relatedness. J. Exp. Mar. Bio. Ecol. 476, 72-77. doi:10.1016/j.jembe.2015.12.008

Boyd, R., and Richerson, P. J. (1985). Culture and the Evolutionary Process. Chicago, IL: University of Chicago Press.

Brakes, P., and Simmonds, M. P. (2011). Whales and Dolphins: Cognition, Culture, Conservation and Human Perceptions. London: Routledge.

Brent, L. J. N., Franks, D. W., Cant, M. A., Croft, D. P., Brent, L. J. N., Franks, D. W., et al. (2015). Ecological knowledge, leadership, and the evolution of menopause in killer whales. Curr. Biol. 25, 1-5. doi: 10.1016/j.cub.2015. 01.037

Brown, A. M., Kopps, A. M., Allen, S. J., Bejder, L., Littleford-Colquhoun, B., Parra, G. J., et al. (2014). Population differentiation and hybridisation of Australian snubfin (orcaella heinsohni) and indo-pacific humpback (sousa chinensis) dolphins in North-Western Australia. PLoS ONE 9:e101427. doi: 10.1371/journal.pone.0101427

Brown, J. L. (1969). The buffer effect and productivity in tit populations. Am. Nat. 103, 347. doi: 10.1086/282607

Candolin, U., and Wong, B. B. M. (2012). Behavioural Responses to a Changing World: Mechanisms and Consequences. Oxford: Oxford University Press.

Cantor, M., Shoemaker, L. G., Cabral, R. B., Flores, C. O., Varga, M., and Whitehead, H. (2015). Multilevel animal societies can emerge from cultural transmission. Nat. Commun. 6, 8091. doi: 10.1038/ncomm s9091

Carere, C., and Maestripieri, D. (2013). Animal Personalities: Behavior, Physiology, and Evolution. University of Chicago Press. Available online at: https://books. google.co.nz/books/about/Animal_Personalities.html?id = bBTZXOWoae8C\& pgis $=1$ (Accessed May 4, 2016).
Caro, T. M., and Durant, S. M. (1995). “The importance of behavioural ecology for conservation biology: examples from serengeti carnivores," in Serengeti II: Dynamics, Management, and Conservation of an Ecosystem, eds A. R. E. Sinclair and P. Arcese (Chicago, IL: University of Chicago Press), 451-472.

Carroll, E. L., Fewster, R. M., Childerhouse, S. J., Patenaude, N. J., Boren, L., and Baker, C. S. (2016). First direct evidence for natal wintering ground fidelity and estimate of juvenile survival in the New Zealand southern right whale Eubalaena australis. PLoS ONE 11:e0146590. doi: 10.1371/journal.pone.0146590

Carroll, E. L., Rayment, W. J., Alexander, A. M., Baker, C. S., Patenaude, N. J., Steel, D., et al. (2014). Reestablishment of former wintering grounds by New Zealand southern right whales. Mar. Mammal Sci. 30, 206-220. doi: 10.1111/mms.12031

Carroll, E., Patenaude, N., Alexander, A., Steel, D., Harcourt, R., Childerhouse, S., et al. (2011). Population structure and individual movement of southern right whales around New Zealand and Australia. Mar. Ecol. Prog. Ser. 432, 257-268. doi: 10.3354/meps09145

Castellote, M., Clark, C. W., and Lammers, M. O. (2012). Acoustic and behavioural changes by fin whales (Balaenoptera physalus) in response to shipping and airgun noise. Biol. Conserv. 147, 115-122. doi: 10.1016/j.biocon.2011.12.021

Chilvers, L. B., Corkeron, P. J., Chilvers, B. L., and Corkeron, P. J. (2001). Trawling and bottlenose dolphins' social structure. Proc. R. Soc. Lond. B Biol. Sci. 268, 1901-1905. doi: 10.1098/rspb.2001.1732

Clapham, P. J., Aguilar, A., and Hatch, L. T. (2008). Determining spatial and temporal scales for management: lessons from whaling. Mar. Mammal Sci. 24, 183-201. doi: 10.1111/j.1748-7692.2007.00175.x

Clark, C. W. (1990). Mathematical Bioeconomics. New York, NY: WileyInterscience.

Clarke, R., Aguayo, A., and Paliza, O. (1980). Pregnancy rates of sperm whales in the southeast pacific between 1959 and 1962 and in comparison with those from Paita, Peru between 1975 and 1977. Rep. Int. Whal. Comm. Spec. 2: 151-158.

CMS (2014). Report of the CMS Scientific Council Workshop on the Conservation Implications of Cetacean Culture. Available online at: http://www.cms.int/ sites/default/files/document/Inf_10_14_ScC_WG_Rpt_on_Cetacean_Culture_ Eonly.pdf

Colbeck, G. J., Duchesne, P., Postma, L. D., Lesage, V., Hammill, M. O., and Turgeon, J. (2013). Groups of related belugas (Delphinapterus leucas) travel together during their seasonal migrations in and around Hudson Bay. Proc. Biol. Sci. 280:20122552. doi: 10.1098/rspb.2012.2552

Dall, S. R. X., and Griffith, S. C. (2014). An empiricist guide to animal personality variation in ecology and evolution. Front. Ecol. Evol. 2:3. doi: $10.3389 /$ fevo. 2014.00003

Daura-Jorge, F. G., Cantor, M., Ingram, S. N., Lusseau, D., and Simões-Lopes, P. C. (2012). The structure of a bottlenose dolphin society is coupled to a unique foraging cooperation with artisanal fishermen. Biol. Lett. 8, 702-705. doi: 10.1098/rsbl.2012.0174

Davies, N. B., Krebs, J. R., and West, S. (2012). An Introduction to Behavioural Ecology. Chichester: Wiley-Blackwell.

DeMaster, D. P., Fowler, C. W., Perry, S. L., and Richlen, M. F. (2001). Predation and competition: the impact of fisheries on marine-mammal populations over the next one hundred years. J. Mammal. 82, 641-651. doi: 10.1644/15451542(2001)082<0641:PACTIO>2.0.CO;2

Donaldson, R., Finn, H., Bejder, L., Lusseau, D., and Calver, M. (2012). The social side of human-wildlife interaction: wildlife can learn harmful behaviours from each other. Anim. Conserv. 15, 427-435. doi: 10.1111/j.1469-1795.2012.00548.x

Doney, S. C., Ruckelshaus, M., Emmett Duffy, J., Barry, J. P., Chan, F., and English, C. A., et al. (2012). Climate change impacts on marine ecosystems. Ann. Rev. Mar. Sci. 4, 11-37. doi: 10.1146/annurev-marine-041911-111611

Dunlop, R. A. (2016). The effect of vessel noise on humpback whale, Megaptera novaeangliae, communication behaviour. Anim. Behav. 111, 13-21. doi: 10.1016/j.anbehav.2015.10.002

Durban, J. W., and Pitman, R. L. (2012). Antarctic killer whales make rapid, roundtrip movements to subtropical waters: evidence for physiological maintenance migrations? Biol. Lett. 8, 274-277. doi: 10.1098/rsbl.2011.0875

Erbe, C., Reichmuth, C., Cunningham, K., Lucke, K., and Dooling, R. (2015). Communication masking in marine mammals: a review and research strategy. Mar. Pollut. Bull. 103, 15-38. doi: 10.1016/j.marpolbul.2015.12.007

Esteban, R., Verborgh, P., Gauffier, P., Giménez, J., Foote, A. D., and de Stephanis, R. (2016a). Maternal kinship and fisheries interaction influence killer whale 
social structure. Behav. Ecol. Sociobiol. 70, 111-122. doi: 10.1007/s00265-0152029-3

Esteban, R., Verborgh, P., Gauffier, P., Giménez, J., Guinet, C., and de Stephanis, R. (2016b). Dynamics of killer whale, bluefin tuna and human fisheries in the strait of gibraltar. Biol. Conserv. 194, 31-38. doi: 10.1016/j.biocon.2015.11.031

Estes, J. A., Riedman, M. L., Staedler, M. M., Tinker, M. T., and Lyon, B. E. (2003). Individual variation in prey selection by sea otters: patterns, causes and implications. J. Anim. Ecol. 72, 144-155. doi: 10.1046/j.1365-2656.2003.00690.x

Ferguson, S. H., Higdon, J. W., and Chmelnitsky, E. G. (2010). The rise of killer whales as a major Arctic predator. in A Little Less Arctic: Top Predators in the World's Largest Northern Inland Sea, Hudson Bay, eds S. H. Ferguson, L. L. Loseto, and M. L. Mallory (Dordrecht: Springer), 117-136.

Filatova, O. A., Burdin, A. M., and Hoyt, E. (2013). Is killer whale dialect evolution random? Behav. Processes 99, 34-41. doi: 10.1016/j.beproc.2013.06.008

Foote, A. D., Thomsen, P. F., Sveegaard, S., Wahlberg, M., Kielgast, J., Kyhn, L. A., et al. (2012). Investigating the potential use of environmental DNA (eDNA) for genetic monitoring of marine mammals. PLoS ONE 7:e41781. doi: 10.1371/journal.pone.0041781

Ford, J. K. B., and Ellis, G. M. (2006). Selective foraging by fish-eating killer whales Orcinus orca in British Columbia. Mar. Ecol. Prog. Ser. 316, 185-199. doi: $10.3354 /$ meps316185

Ford, J. K. B., Ellis, G. M., Olesiuk, P. F., and Balcomb, K. C. (2010). Linking killer whale survival and prey abundance: food limitation in the oceans' apex predator? Biol. Lett. 6, 139-142. doi: 10.1098/rsbl.2009.0468

Frasier, T. R., Gillett, R. M., Hamilton, P. K., Brown, M. W., Kraus, S. D., and White, B. N. (2013). Postcopulatory selection for dissimilar gametes maintains heterozygosity in the endangered North Atlantic right whale. Ecol. Evol. 3, 3483-3494. doi: 10.1002/ece3.738

Game, E. T., Bode, M., McDonald-Madden, E., Grantham, H. S., and Possingham, H. P. (2009). Dynamic marine protected areas can improve the resilience of coral reef systems. Ecol. Lett. 12, 1336-1346. doi: 10.1111/j.14610248.2009.01384.x

Garland, E. C., Goldizen, A. W., Rekdahl, M. L., Constantine, R., Garrigue, C., Hauser, N. D., et al. (2011). Dynamic horizontal cultural transmission of humpback whale song at the ocean basin scale. Curr. Biol. 21, 687-691. doi: 10.1016/j.cub.2011.03.019

Garland, E. C., Noad, M. J., Goldizen, A. W., Lilley, M. S., Rekdahl, M. L., Garrigue, C., et al. (2013). Quantifying humpback whale song sequences to understand the dynamics of song exchange at the ocean basin scale. J. Acoust. Soc. Am. 133, 560-569. doi: 10.1121/1.4770232

Gaydos, J. K., Ignacio Vilchis, L., Lance, M. M., Jeffries, S. J., Thomas, A., Greenwood, V., et al. (2013). Postrelease movement of rehabilitated harbor seal (Phoca Vitulina Richardii) pups compared with cohort-matched wild seal pups. Mar. Mammal Sci. 29. doi: 10.1111/mms.12002

Gelatt, T. S., Davis, C. S., Stirling, I., Siniff, D. B., Strobeck, C., and Delisle, I. (2010). History and fate of a small isolated population of Weddell seals at White Island, Antarctica. Conserv. Genet. 11, 721-735. doi: 10.1007/s10592-0099856-6

Gonçalves, L. R., Augustowski, M., and Andriolo, A. (2015). Occurrence, distribution and behaviour of Bryde's whales (Cetacea: Mysticeti) off south-east Brazil. J. Mar. Biol. Assoc. U.K. 1-12. doi: 10.1017/S0025315415001812

Greggor, A. L., Clayton, N. S., Phalan, B., and Thornton, A. (2014). Comparative cognition for conservationists. Trends Ecol. Evol. 29, 489-495. doi: 10.1016/j.tree.2014.06.004

Guénette, S., Heymans, S. J. J. J., Christensen, V., and Trites, A. W. (2006). Ecosystem models show combined effects of fishing, predation, competition, and ocean productivity on Steller sea lions (Eumetopias jubatus) in Alaska. Can. J. Fish. Aquat. Sci. 63, 2495-2517. doi: 10.1139/f06-136

Henderson, N., and Sutherland, W. J. (1996). Two truths about discounting and their environmental consequences. Trends Ecol. Evol. 11, 527-528. doi: 10.1016/S0169-5347(96)20083-7

Hodgins, N. K., Dolman, S. J., and Weir, C. R. (2014). Potential hybridism between free-ranging Risso's dolphins (Grampus griseus) and bottlenose dolphins (Tursiops truncatus) off north-east Lewis (Hebrides, UK). Mar. Biodivers. Rec. 7, 1-7. doi: 10.1017/S175526721400089X

Hoelzel, A. R., Goldsworthy, S. D., and Fleischer, R. C. (2009). "Population genetic structure," in Marine Mammal Biology: An Evolutionary Approach, ed A. R. Hoelzel (Oxford: Blackwell Science), 325-352.
Hoyt, E. (2009). "Marine Protected Areas," in Encyclopedia of Marine Mammals, eds W. F. Perrin, B. Wursig, and J. G. M. Thewissen (San Diego, CA: Academic Press), 696-704.

Hoyt, E. (2011). Marine Protected Areas for Whales, Dolphins, and Porpoises: A World Handbook for Cetacean Habitat Conservation and Planning. Routledge.

Huisman, J., Kruuk, L. E. B., Ellis, P. A., Clutton-Brock, T., and Pemberton, J. M. (2016). Inbreeding depression across the lifespan in a wild mammal population. Proc. Natl. Acad. Sci. U.S.A. 113, 201518046. doi: 10.1073/pnas.1518046113

Ivashchenko, Y. V., and Clapham, P. J. (2015). What's the catch? validity of whaling data for Japanese catches of sperm whales in the North Pacific. R. Soc. Open Sci. 2:150177. doi: 10.1098/rsos.150177

Ivashchenko, Y. V., Clapham, P. J., and Brownell, R. L. (2011). Soviet illegal whaling: the devil and the detail. Mar. Fish. Rev. 73, 1-19.

Jett, J., and Ventre, J. (2015). Captive killer whale (Orcinus orca) survival. Mar. Mammal Sci. 31, 1362-1377. doi: 10.1111/mms.12225

Katona, S. K., and Kraus, S. D. (1999). "Efforts to conserve the North Atlantic right whale," in Conservation Management of Marine Mammals, eds J. Twiss and R. RR (Washington, DC: Smithsonian), 311-331.

Kellert, S. R. (1993). Attitudes, knowledge, and behavior toward wildlife among the industrial superpowers: United States, Japan, and Germany. J. Soc. Issues 49, 53-69. doi: 10.1111/j.1540-4560.1993.tb00908.x

Kershaw, P. J. (2015). Biodegradable Plastics and Marine Litter: Misconceptions, Concerns and Impacts on Our Marine Environments. Available online at: http:// unep.org/gpa/documents/publications/BiodegradablePlastics.pdf (Accessed February 24, 2016).

Kovacs, K. M., Lydersen, C., Overland, J. E., and Moore, S. E. (2011). Impacts of changing sea-ice conditions on Arctic marine mammals. Mar. Biodivers. 41, 181-194. doi: 10.1007/s12526-010-0061-0

Kraus, S. D., Hamilton, P. K., Kenney, R. D., Knowlton, A. R., and Slay, C. K. (2001). Reproductive parameters of the North Atlantic right whale. J. Cetacean Res. Manag. 2, 231-236.

Krause, J., and Ruxton, G. D. (2002). Living in Groups. Oxford: Oxford University Press.

Kurvers, R. H. J. M., Krause, J., Croft, D. P., Wilson, A. D. M., and Wolf, M. (2014). The evolutionary and ecological consequences of animal social networks: emerging issues. Trends Ecol. Evol. 1-10. doi: 10.1016/j.tree.2014.04.002

Lafferty, K. D., and Tinker, M. T. (2014). Sea otters are recolonizing southern California in fits and starts. Ecosphere 5, 1-11. doi: 10.1890/ES13-00394.1

Lambert, E., MacLeod, C. D., Hall, K., Brereton, T., Dunn, T. E., Wall, D., et al. (2011). Quantifying likely cetacean range shifts in response to global climatic change: implications for conservation strategies in a changing world. Endanger. Species Res. 15, 205-222. doi: 10.3354/esr00376

Lancaster, M. L., Goldsworthy, S. D., and Sunnucks, P. (2010). Two behavioural traits promote fine-scale species segregation and moderate hybridisation in a recovering sympatric fur seal population. BMC Evol. Biol. 10:143. doi: 10.1186/1471-2148-10-143

Le Boeuf, B. J., Crocker, D. E., Costa, D. P., Blackwell, S. B., Webb, P. M., and Houser, D. S. (2000). Foraging ecology of Northern elephant seals. Ecol. Monogr. 70, 353-382. doi: 10.2307/2657207

Lomac-Macnair, K., and Smultea, M. A. (2016). Blue whale (Balaenoptera musculus) behavior and group dynamics as observed from an aircraft off Southern California. Anim. Behav. Cogn. 3, 1-21. doi: 10.12966/abc.02. 01.2016

Lombard, E. (1911). Le signe de l'elevation de la voix. Ann. Mal. Oreille, Larynx Nez Pharynx. 37, 101-119.

Luksenburg, J. A., and Parsons, E. C. M. (2014). Attitudes towards marine mammal conservation issues before the introduction of whale-watching: a case study in Aruba (southern Caribbean). Aquat. Conserv. Mar. Freshw. Ecosyst. 24, 135-146. doi: 10.1002/aqc. 2348

Magnúsdóttir, E. E., Miller, P. J. O., Lim, R., Rasmussen, M. H., Lammers, M. O., and Svavarsson, J. (2015). Humpback whale (Megaptera novaeangliae) song unit and phrase repertoire progression on a subarctic feeding ground. J. Acoust. Soc. Am. 138, 3362-3374. doi: 10.1121/1.4935517

Malthus, T. (1798). An Essay on the Principle of Population. London: J Johnson.

Mann, J., and Kemps, C. (2003). "The effects of provisioning on maternal care in wild bottlenose dolphins, Shark Bay, Australia," in Marine Mammals and Humans: Towards a sustainable balance, eds N. Gales, M. Hindell, and R. Kirkwood (Clayton: CSIRO Publishing), 304-320. 
Mann, J., Stanton, M. A., Patterson, E. M., Bienenstock, E. J., and Singh, L. O. (2012). Social networks reveal cultural behaviour in tool-using dolphins. Nat. Commun. 3, 980. doi: 10.1038/ncomms1983

Mate, B. R., Nieukirk, S. L., Kraus, S. D. (1997). Satellite-monitored movements of the northern right whale. J. Wildl. Manage. 61, 1393-1405. doi: $10.2307 / 3802143$

McDonald, M., Hildebrand, J., and Mesnick, S. (2009). Worldwide decline in tonal frequencies of blue whale songs. Endanger. Species Res. 9, 13-21. doi: 10.3354/esr00217

McLeod, B. A., Frasier, T. R., and Lucas, Z. (2014). Assessment of the extirpated maritimes walrus using morphological and ancient DNA analysis. PLoS ONE 9:e99569. doi: 10.1371/journal.pone.0099569

Melcón, M. L., Cummins, A. J., Kerosky, S. M., Roche, L. K., Wiggins, S. M., and Hildebrand, J., a (2012). Blue whales respond to anthropogenic noise. PLoS ONE 7:e32681. doi: 10.1371/journal.pone.0032681

Mesoudi, A., Chang, L., Dall, S. R. X., and Thornton, A. (2016). The evolution of individual and cultural variation in social learning. Trends Ecol. Evol. 31, 1-11. doi: $10.1016 /$ j.tree.2015.12.012

Moore, M., Early, G., Touhey, K., Barco, S., Gulland, F., and Wells, R. (2007). Rehabilitation and release of marine mammals in the United States: risks and benefits. Mar. Mammal Sci. 23, 731-750. doi: 10.1111/j.1748-7692.2007.00146.x

Moore, S. E., and Huntington, H. P. (2008). Arctic marine mammals and climate change: impacts and resilience. Ecol. Appl. 18, S157-S165. doi: 10.1890/060571.1

Morissette, L., Christensen, V., and Pauly, D. (2012). Marine mammal impacts in exploited ecosystems: would large scale culling benefit fisheries? PLOS ONE 7:e43966. doi: 10.1371/journal.pone.0043966

NOAA (2015). North Atlantic Right Whale (Eubalaena glacialis): Western Atlantic Stock. Available online at: http://nefsc.noaa.gov/publications/tm/tm231/ 7_rightwhale_F2014July.pdf (Accessed February 26, 2016).

Noad, M. J., Cato, D. H., Bryden, M. M., Jenner, M.-N., and Jenner, K. C. S. (2000). Cultural revolution in whale songs. Nature 408, 537-538. doi: $10.1038 / 35046199$

Osborne, R. W. (1999). A Historical Ecology of SALISH SEA "Resident" Killer Whales (Orcinus orca): with Implications for Management. Ph.D., dissertation.

Pace, D. S., Pulcini, M., and Triossi, F. (2011). Anthropogenic food patches and association patterns of Tursiops truncatus at Lampedusa island, Italy. Behav. Ecol. 23, 254-264. doi: 10.1093/beheco/arr180

Parsons, E., Baulch, S., Bechshoft, T., Bellazzi, G., Bouchet, P., Cosentino, A., et al. (2015). Key research questions of global importance for cetacean conservation. Endanger. Species Res. 27, 113-118. doi: 10.3354/esr00655

Parsons, E. C. M., Wright, A. J., and Gore, M. A. (2008). The nature of humpback whale (Megaptera Novaeangliae) song. J. Mar. Anim. Their Ecol. 1, 21-30. doi: 10.3354/esr00655

Pennock, D. S., and Dimmick, W. W. (1997). Critique of the evolutionarily significant unit as a definition for "distinct population segments" under the U.S. Endangered species Act. Conserv. Biol. 11, 611-619. doi: 10.1046/j.15231739.1997.96109.x

Pitman, R. L., Durban, J. W., Greenfelder, M., Guinet, C., Jorgensen, M., Olson, P. A., et al. (2010). Observations of a distinctive morphotype of killer whale (Orcinus orca), type D, from subantarctic waters. Polar Biol. 34, 303-306. doi: 10.1007/s00300-010-0871-3

Prins, H. T., and Gordon, I. J. (2014). Invasion Biology and Ecological Theory: Insights from a Continent in Transformation. Cambridge: Cambridge University Press.

Rendell, L., Mesnick, S. L., Dalebout, M. L., Burtenshaw, J., and Whitehead, H. (2012). Can genetic differences explain vocal dialect variation in sperm whales, Physeter macrocephalus? Behav. Genet. 42, 332-343. doi: 10.1007/s10519-0119513-y

Rendell, L., and Whitehead, H. (2001). Culture in whales and dolphins. Behav. Brain Sci. 24, 309-382. doi: 10.1017/S0140525X0100396X

Riesch, R., Barrett-Lennard, L. G., Ellis, G. M., Ford, J. K. B., and Deecke, V. B. (2012). Cultural traditions and the evolution of reproductive isolation: ecological speciation in killer whales? Biol. J. Linn. Soc. 106, 1-17. doi: 10.1111/j.1095-8312.2012.01872.x

Rode, K. D., Regehr, E. V., Douglas, D. C., Durner, G., Derocher, A. E., Thiemann, G. W., et al. (2014). Variation in the response of an Arctic top predator experiencing habitat loss: Feeding and reproductive ecology of two polar bear populations. Glob. Chang. Biol. 20, 76-88. doi: 10.1111/gcb.12339

Roman, J., and Palumbi, S. R. (2003). Whales before whaling in the North Atlantic. Science 301, 508-510. doi: 10.1126/science.1084524

Schaeff, C. M., Kraus, S. D., Brown, M. W., Perkins, J. S., Payne, R., and White, B. N. (1997). Comparison of genetic variability of North and South Atlantic right whales (Eubalaena), using DNA fingerprinting. Can. J. Zool. 75, 1073-1080. doi: 10.1139/z97-129

Schakner, Z. A., and Blumstein, D. T. (2013). Behavioral biology of marine mammal deterrents: a review and prospectus. Biol. Conserv. 167, 380-389. doi: 10.1016/j.biocon.2013.08.024

Schaurich, M. D. N., Lopes, V., Ricardo, F., and de Oliveira, L. R. (2012). Hybridization phenomenon in cetacean and pinniped species. Neotrop. Biol. Conserv. 7, 199-209. doi: 10.4013/nbc.2012.73.06

Sharp, S. M., Harry, C. T., Hoppe, J. M., Moore, K. M., Niemeyer, M. E., Robinson, I., et al. (2016). A comparison of postrelease survival parameters between single and mass stranded delphinids from Cape Cod, Massachusetts, U.S.A. Mar. Mammal Sci. 32, 161-180. doi: 10.1111/mms.12255

Sih, A., Bell, A. M., Johnson, J. C., and Ziemba, R. E. (2004). Behavioral syndromes: an integrative overview. Q. Rev. Biol. 79, 241-177. doi: 10.1086/4 22893

Sih, A., Ferrari, M. C. O., and Harris, D. J. (2011). Evolution and behavioural responses to human-induced rapid environmental change. Evol. Appl. 4, 367-387. doi: 10.1111/j.1752-4571.2010.00166.x

Simmonds, M. P. (2012). Cetaceans and marine debris: the great unknown. J. Mar. Biol. 2012, 1-8. doi: 10.1155/2012/684279

Simon, M., Hanson, M. B., Murrey, L., Tougaard, J., and Ugarte, F. (2009). From captivity to the wild and back: an attempt to release Keiko the killer whale. Mar. Mammal Sci. 25, 693-705. doi: 10.1111/j.1748-7692.2009.00287.x

Small, R. J., and Demaster, D. P. (1995). Survival of five species of captive marine mammals. Mar. Mammal Sci. 11, 209-226. doi: 10.1111/j.17487692.1995.tb00519.x

Sobel, J. M., Chen, G. F., Watt, L. R., and Schemske, D. W. (2010). The biology of speciation. Evolution (N.Y). 64, 295-315. doi: 10.1111/j.15585646.2009.00877.x

Stephens, P. A., Sutherland, W. J., and Freckleton, R. P. (1999). What is the Allee effect? Oikos 87, 185-190. doi: 10.2307/3547011

Stirling, I., and Derocher, A. E. (2012). Effects of climate warming on polar bears: a review of the evidence. Glob. Chang. Biol. 18, 2694-2706. doi: 10.1111/j.13652486.2012.02753.x

Sutherland, W. (1998). The importance of behavioural studies in conservation biology. Anim. Behav. 56, 801-809. doi: 10.1006/anbe.1998.0896

Sutherland, W. J. (1995). From Individual Behaviour to Population Ecology. Oxford: Oxford University Press.

Sutherland, W. J. (1996). Predicting the consequences of habitat loss for migratory populations. Proc. R. Soc. B Biol. Sci. 263, 1325-1327. doi: $10.1098 /$ rspb.1996.0194

Tablado, Z., and Jenni, L. (2015). Determinants of uncertainty in wildlife responses to human disturbance. Biol. Rev. doi: 10.1111/brv.12224. [Epub ahead of print].

Thode, A., Mathias, D., Straley, J., Connell, V. O., Behnken, L., Falvey, D., et al. (2015). Cues, creaks and decoys: using passive acoustic monitoring as a tool for studying sperm whale depredation. ICES J. Mar. Sci. 72, 1621-1636. doi: 10.1093/icesjms/fsv024

Thornton, A., and Clutton-Brock, T. (2011). Social learning and the development of individual and group behaviour in mammal societies. Philos. Trans. R. Soc. Lond. B Biol. Sci. 366, 978-987. doi: 10.1098/rstb.2010.0312

Tinker, M. T., Bentall, G., and Estes, J. A. (2008). Food limitation leads to behavioral diversification and dietary specialization in sea otters. Proc. Natl. Acad. Sci. U.S.A. 105, 560-565. doi: 10.1073/pnas.07092 63105

Tixier, P., Gasco, N., Duhamel, G., and Guinet, C. (2015). Habituation to an acoustic harassment device (AHD) by killer whales depredating demersal longlines. ICES J. Mar. Sci. 72, 1673-1681. doi: 10.1093/icesjms/fsul66

Twiss, S. D., Cairns, C., Culloch, R. M., Richards, S. A., and Pomeroy, P. P. (2012). Variation in female grey seal (Halichoerus grypus) reproductive performance correlates to proactive-reactive behavioural types. PLOS ONE 7:e49598. doi: 10.1371/journal.pone.0049598 
UNESCO (2016). What is Intangible Cultural Heritage? Available online at: http:// www.unesco.org/culture/ich/en/what-is-intangible-heritage-00003 (Accessed February 24, 2016).

UNFPA (2011). The World at Seven Billion. UNFPA - United Nations Fund Popul. Act. Available online at: http://www.unfpa.org/sites/default/files/resource-pdf/ 7B_fact_sheets_en.pdf (Accessed February 24, 2016).

Veirs, S., Veirs, V., and Wood, J. (2015). Ship noise extends to frequencies used for echolocation by endangered killer whales. Peer J. Prepr. 4:e1657. doi: 10.7717/peerj.1657

Wade, P. R., Reeves, R. R., and Mesnick, S. L. (2012). Social and Behavioural factors in cetacean responses to overexploitation: are odontocetes less "resilient" than mysticetes? J. Mar. Biol. 2012, 1-15. doi: 10.1155/2012/567276

Waldick, R. C., Kraus, S., Brown, M., and White, B. N. (2002). Evaluating the effects of historic bottleneck events: an assessment of microsatellite variability in the endangered, North Atlantic right whale. Mol. Ecol. 11, 2241-2250. doi: 10.1046/j.1365-294X.2002.01605.x

Waters, C. N., Zalasiewicz, J., Summerhayes, C., Barnosky, A. D., Poirier, C., $\mathrm{Ga}, \mathrm{A}$., et al. (2016). The anthropocene is functionally and stratigraphically distinct from the Holocene. Science 351, aad2622-1-aad2622-10. doi: $10.1126 /$ science.aad 2622

Weber, D. S., Stewart, B. S., Schienman, J., and Lehman, N. (2004). Major histocompatibility complex variation at three class II loci in the northern elephant seal. Mol. Ecol. 13, 711-718. doi: 10.1111/j.1365-294X.2004.02095.x

Whitehead, H. (1994). Delayed competitive breeding in roving males. J. Theor. Biol. 166, 127-133. doi: 10.1006/jtbi.1994.1011

Whitehead, H. (2003). Sperm Whales: Social Evolution in the Ocean. Chicago, IL: University of Chicago Press.

Whitehead, H. (2010). Conserving and managing animals that learn socially and share cultures. Learn. Behav. 38, 329-336. doi: 10.3758/LB.38.3.329

Whitehead, H., Antunes, R., Gero, S., Wong, S. N. P., Engelhaupt, D., and Rendell, L. (2012). Multilevel societies of female sperm whales (Physeter Macrocephalus) in the Atlantic and Pacific: why are they so different? Int. J. Primatol. 33, 1142-1164. doi: 10.1007/s10764-012-9598-Z

Whitehead, H., Christal, J., and Dufault, S. (1997). Past and distant whaling and the rapid decline of sperm whales off the Galapagos Islands. Conserv. Biol. 11, 1387-1396. doi: 10.1046/j.1523-1739.1997.96246.x

Whitehead, H., and Hope, P. L. (1991). Sperm whalers off the Galapagos Islands and in the Western North Pacific, 1830-1850: Ideal free whalers? Ethol. Sociobiol. 12, 147-161. doi: 10.1016/0162-3095(91)90018-L
Whitehead, H., and Rendell, L. (2015). The Cultural Lives of Whales and Dolphins University of Chicago Press. Available online at: https://books.google.com/ books?id=GeBXBQAAQBAJ\&pgis=1 (Accessed September 21, 2015).

Whitehead, H., Rendell, L., Osborne, R. W., and Würsig, B. (2004). Culture and conservation of non-humans with reference to whales and dolphins: review and new directions. Biol. Conserv. 120, 427-437. doi: 10.1016/j.biocon.2004.03.017

Williams, R., Erbe, C., Ashe, E., and Clark, C. W. (2015). Quiet(er) marine protected areas. Mar. Pollut. Bull. 100, 154-161. doi: 10.1016/j.marpolbul.2015.09.012

Williams, R., and Lusseau, D. (2006). A killer whale social network is vulnerable to targeted removals. Biol. Lett. 2, 497-500. doi: 10.1098/rsbl.2006.0510

Wirsing, A. J., and Heithaus, M. R. (2012). Behavioural transition probabilities in dugongs change with habitat and predator presence: implications for sirenian conservation. Mar. Freshw. Res. 63, 1069-1076. doi: 10.1071/MF 12074

Wolf, M., and Weissing, F. J. (2012). Animal personalities: consequences for ecology and evolution. Trends Ecol. Evol. 27, 452-461. doi: 10.1016/j.tree.2012.05.001

Yack, T. M., Barlow, J., Calambokidis, J., Southall, B., and Coates, S. (2013). Passive acoustic monitoring using a towed hydrophone array results in identification of a previously unknown beaked whale habitat. J. Acoust. Soc. Am. 134, 2589-2595. doi: 10.1121/1.4816585

Yodzis, P. (2001). Culling predators to protect fisheries: a case of accumulating uncertainty. Trends Ecol. Evol. 16, 282-283. doi: 10.1016/S0169-5347(01)02159-0

Zhan, X., Li, M., Zhang, Z., Goossens, B., Chen, Y., Wang, H., et al. (2006). Molecular censusing doubles giant panda population estimate in a key nature reserve. Curr. Biol. 16, R451-R452. doi: 10.1016/j.cub.2006.05.042

Conflict of Interest Statement: The authors declare that the research was conducted in the absence of any commercial or financial relationships that could be construed as a potential conflict of interest.

Copyright (c) 2016 Brakes and Dall. This is an open-access article distributed under the terms of the Creative Commons Attribution License (CC BY). The use, distribution or reproduction in other forums is permitted, provided the original author(s) or licensor are credited and that the original publication in this journal is cited, in accordance with accepted academic practice. No use, distribution or reproduction is permitted which does not comply with these terms. 